\title{
One health pathogen surveillance demonstrated the dissemination of gut pathogens within the two coastal regions associated with intensive farming
}

\author{
Qingyao Wang ${ }^{1,2+}$, Yixiang Zhang ${ }^{3,4 \dagger}$, Qian Yang ${ }^{5}$, Songzhe Fu ${ }^{1,2^{*}} \mathbb{C}$, Baocheng Qu ${ }^{1,2}$ and Tom Defoirdt ${ }^{5}$
}

\begin{abstract}
Background: Intensive aquaculture farming has caused significant degradation of coastal wetlands and has been proposed as a reservoir for pathogenic Vibrio spp.

Results: Gut pathogens including Vibrio spp., Salmonella spp., and Klebsiella spp. were isolated from bird feces, shrimp and wetland water in two typical coastal regions of China in 2015 and 2017 and were subsequently subjected to whole-genome sequencing. Meanwhile, local patient isolates were also selected to confirm the epidemiological links. Bacterial community composition analyses of the sediments that were sampled in 2015 and 2017 were conducted by the hypervariable region 4 of the 165 rRNA gene. Together with the local clinical isolates, we observed highly related Vibrio isolates from waterbirds, wetlands and shrimp. Phylogenetic genome comparisons also demonstrated that sequence types ST3 and ST2414 Vibrio parahaemolyticus isolates obtained from aquatic animals were clonally related to patient isolates. Likewise, three Salmonella typhimurium isolates were also genomically related to one clinical strain. The results showed that farming activities significantly altered the community composition and resulted in the emergence of several pathogens, including Acinetobacter, Mycobacterium and Legionella.
\end{abstract}

Conclusions: In conclusion, our results demonstrated that intensive shrimp farming in wetlands has two devastating impacts: pathogen dissemination from aquatic animals into migratory birds and transmission of foodborne pathogens into local communities.

Keywords: Vibrio parahaemolyticus, Vibrio vulnificus, Wetlands, One health, Shrimp farming

\section{Background}

Destruction of animal habitats has been associated with infectious disease emergence [1-3]. For instance, the outbreaks of Ebola in humans are linked to the deforestation in West Africa [4]. Coastal wetlands are another destruction hotspot and face a range of anthropogenic threats,

\footnotetext{
*Correspondence: fusongzhe@dlou.edu.cn

${ }^{\dagger}$ Qingyao Wang and Yixiang Zhang contributed equally to this paper

${ }^{1}$ College of Marine Science and Environment, Dalian Ocean University,

No. 52 Heishijiao Street, Dalian 116023, China

Full list of author information is available at the end of the article
}

the most widespread and alarming of which are those posed by commercial shrimp farming [5]. Extensive loss and degradation of wetland ecosystems is also an emerging issue in China. In the recent decade, the booming of the intensive coastal farming has resulted in rapid shrinking of coastal wetlands in China. China's coastal areas have gradually lost more than 1 million hectares in the past four decades, equivalent to $50 \%$ of the total area of coastal wetlands [6]. Due to the favorable climate and availability of space, shrimp farming has mainly developed in the tropical and subtropical coastal lowlands. In China alone, the majority of shrimp consumed are original author(s) and the source, provide a link to the Creative Commons licence, and indicate if changes were made. The images or other third party material in this article are included in the article's Creative Commons licence, unless indicated otherwise in a credit line to the material. If material is not included in the article's Creative Commons licence and your intended use is not permitted by statutory regulation or exceeds the permitted use, you will need to obtain permission directly from the copyright holder. To view a copy of this licence, visit http://creativecommons.org/licenses/by/4.0/. The Creative Commons Public Domain Dedication waiver (http://creativeco mmons.org/publicdomain/zero/1.0/) applies to the data made available in this article, unless otherwise stated in a credit line to the data. 
farmed in the coastal regions with an annual production of 1.76 million tons [7]. Shrimp farms require substantial quantities of water, and are primarily located alongside rivers, estuaries and coastal areas. Consequently, the rapid expansion of shrimp farming results in quick loss of coastal wetlands. For instance, Valiela et al. [8] have reported that conversion from wetland to shrimp farm is responsible for water pollution and 38\% of total mangrove loss, and this is the most significant cause of mangrove loss.

Apart from wetland habitat loss and environmental pollution, another neglected issue is that as a large number of wetlands have been converted into shrimp ponds, the spillover effects of pathogens from shrimp farms into the environment and its threat to the public health have rarely been examined. Our previous study found that a widespread use of pathogen-contaminated probiotic agents in the farm would result in the spillover of pathogens such as Bacillus cereus from farm to environment, which might lead to human infections [9].

Bacterial enteric pathogens are responsible for a majority of diarrheal illness associated with the consumption of contaminated seafood [10,11], of which Vibrio species are most widespread in estuaries and shrimp farms [12-14]. Pathogenic Vibrio species including O1 and non-O1 V. cholerae, and V. parahaemolyticus, have been commonly identified in shrimp farms [15, 16]. Besides, Salmonella spp., and Escherichia coli were also frequently detected in cultured shrimp and aquatic environment $[17,18]$. In intensive farming systems, physico-chemical factors such as the ammonia concentration, temperature, and dissolved organic carbon levels fluctuate frequently, which may favor the growth of bacterial enteric pathogens species and result in a high abundance of pathogens in the shrimp ponds, which pose a significant health risk for the consumer [19].

Intensive shrimp farming might also accelerate the transfer of pathogens from shrimp and other aquatic animals to water birds. Recent studies revealed that wetlands, the natural food sources of water birds, are undergoing a rapid decline. With the rapid expansion of aquaculture, most of the wetlands are surrounded by a large area of intensive aquafarms in China. Zhang et al. [20] also found that the natural food for bar-tailed birds rapidly disappeared but without the decline of the number of water birds, raising the speculation that waterbirds might seek for alternative shellfish or other animals from nearby aquafarms. Our previous study further suggested that direct predation of aquatic animals was an important source of bird-carried Vibrio spp. [21]. Although pathogen emergence is thought to be associated with wetland conversion, clear mechanisms have not been demonstrated. One hypothesis is that edges between core and matrix wetland facilitate interspecies contact and pathogen transfer during land conversion [22]. Yet, epidemiological links between pathogens in animals and clinical samples have not been investigated. Pathogens carried by water birds and the epidemiological relationships of Vibrio spp. in aquatic animals have been well studied separately but have not yet been integrated $[16,21]$.

To evaluate the impacts of shrimp farming on the pathogen spillover to the nearby wetlands, we selected two coastal regions. One located in the Caofeidian district (CFD) of Tangshan and the other was at Hangzhou Bay (HZB) in Ningbo, both of which are crisscrossed with shrimp farms and wetlands (Fig. 1). Gut pathogens were isolated from shrimps, wetlands and bird feces. Comparative genomic analysis was then conducted with a large dataset of sequenced genomes to determine the origin of bird-carried isolates and environmental strains. Additionally, we also analyzed the dynamics of microbial communities in the sediment of two wetlands from 2015 to 2017, which provides novel insights into the impact of aquaculture activities on the pathogen load in wetlands.

\section{Results \\ Isolation and MLST of Vibrio spp. in shrimp ponds and wetlands}

In 2015, five $V$. parahaemolyticus strains were isolated from the shrimp pond in the CFD, which could be subtyped into sequence types (STs), including ST415, ST1743, and ST424 (Additional file 1: Table S1). However, no pathogenic Vibrio spp. was isolated from water or sediment of the wetland. In 2017, two ST180 strains, one ST12 strain and one ST1800 strain were isolated from both the wetland water and shrimp pond (Table 1). Meanwhile, one $V$. parahaemolyticus strain and one $V$. vulnificus strain were retrieved from two out of 30 bird fecal samples.

In the HZB, no pathogenic Vibrio spp. were isolated from the wetland in 2015, but one $V$. parahaemolyticus strain (ST1808) and two V. campbellii strains were obtained from the nearby shrimp pond. In 2017, three $V$. parahaemolyticus strains were isolated from the shrimp pond, which divided into four STs (ST3, ST302, and ST1803). Meanwhile, one V. tubiashii strain was found in the wetland. In addition, six bird fecal samples were positive for Vibrio spp. in April-2017, including two V. parahaemolyticus strains (ST2414 and ST1), two $V$. campbellii strains, one $V$. diabolicus strain and one $V$. tubiashii strain.

\section{Phylogenetic analysis of $V$. parahaemolyticus confirmed pathogen circulation among birds, shrimp and humans}

To investigate whether there is a pathogen circulation among birds, shrimp and humans, we first conducted 


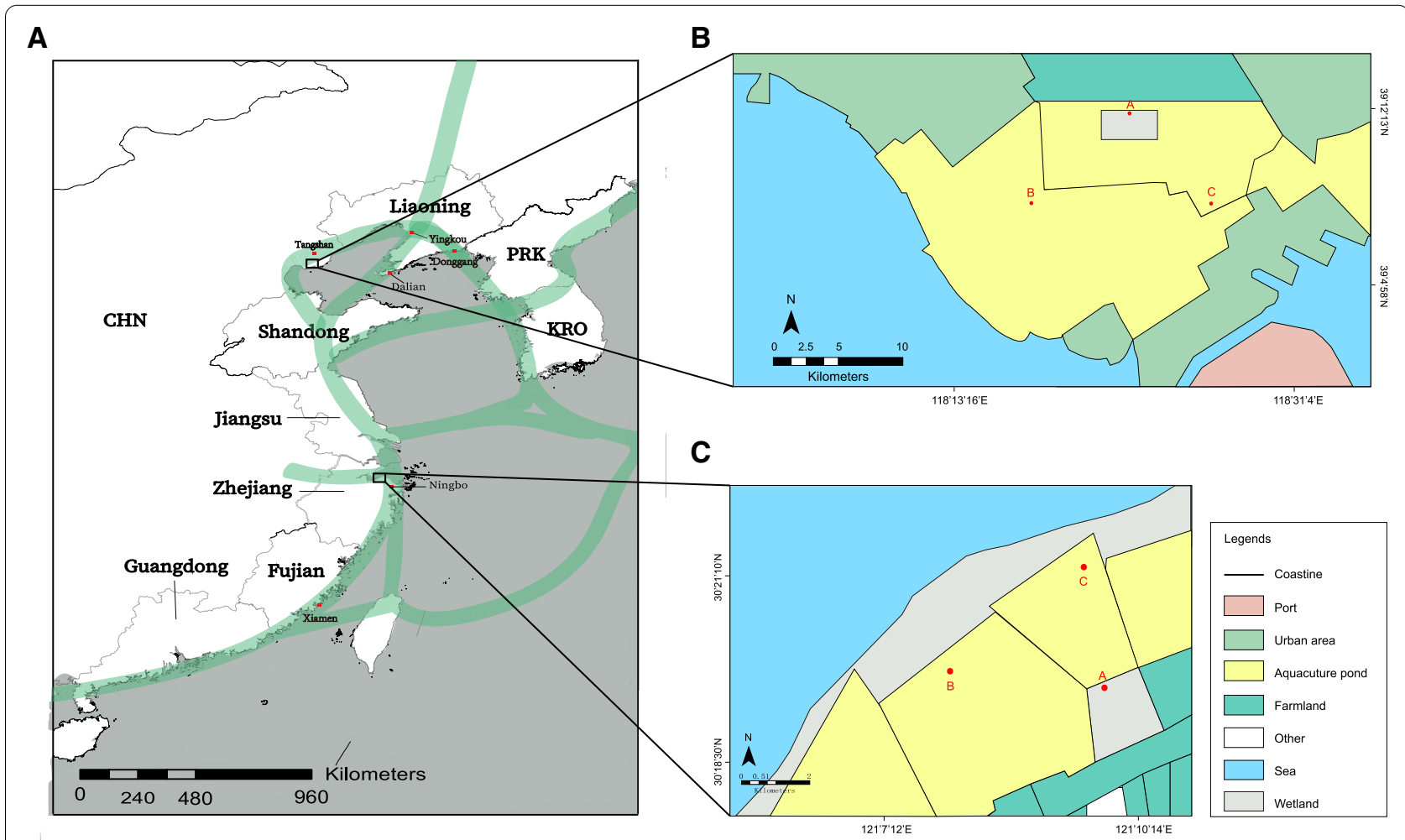

Fig. 1 Migration route of the water birds from South China to North China (A) and three sampling sites in Caofeidian district (B) and Hangzhou Bay $(\mathbf{C})$. Three sampling sites in each region are indicated in red. Green bands: migration route of water birds in the coastal region of China. The migratory information comes from International Union for Conservation of Nature, IUCN. The sampling sites were mapped by the ArcGIS Desktop 10.2 software (http://desktop.arcgis.com/)

whole genome sequencing analysis of $17 \mathrm{~V}$. parahaemolyticus strains and compared them with 91 previously sequenced strains isolated from the two regions (Additional file 1: Table S2). Phylogenetic analysis of the $108 \mathrm{~V}$. parahaemolyticus strains divided them into five clusters (Fig. 2A).

In our dataset, one ST180 isolate, HB18, obtained from Black-tailed Godwit Limosa limosa, was clustered with two isolates from shrimp in the CFD wetland with a maximum of three SNP differences (Fig. 2A). Additionally, the ST693 strain NB80 isolated from bird feces have only 14 SNP differences with strain E7_10 (isolated from fish).

Phylogenetic analysis of three ST189 and 54 ST2414 strains showed that these genomes can be divided into three clusters, the majority of which located in Cluster I, differing by less than 10 SNPs (Fig. 2B). The bird-carried ST2414 isolate NB189 was clustered with two other ST2414 strains (HZ17-143 and HZ17-171), differing by two SNPs.

Notably, one ST3 isolate NB327 was genomically identical to local ST3 strain HZ18-116 (Fig. 2B). Such epidemiological link was also observed in Tangshan; clinical isolate CZ17 has only ten SNP difference from shrimporiginated strain VP175.

\section{Origins of $V$. campbellii, $V$. vulnificus and $V$. tubiashii present in water birds}

We subsequently determined the phylogenetic relationships of four $V$. campbellii strains isolated from this study and $28 \mathrm{~V}$. campbellii strains from publicly available genomes. Two shrimp-carried $V$. campbellii isolates retrieved from Ningbo in 2015 were genomically identical to a bird-carried isolate, and another $V$. campbellii strain (1705021), isolated from shrimp, was clustered with bird-carried strain NB81 (Fig. 3A). In addition, together with three $V$. tubiashii strains available in public databases, five $V$. tubiashii genomes were divided into two branches, of which the bird-carried V. tubiashii isolate NB17 was genomically identical to isolate NB18 (from shrimp), indicating that it is possibly originated from the local shrimp (Fig. 3B).

We further conducted whole genome sequencing for one $V$. vulnificus isolate. Together with 125 publicly available V. vulnificus genomes (Additional file 1: Table S3), 


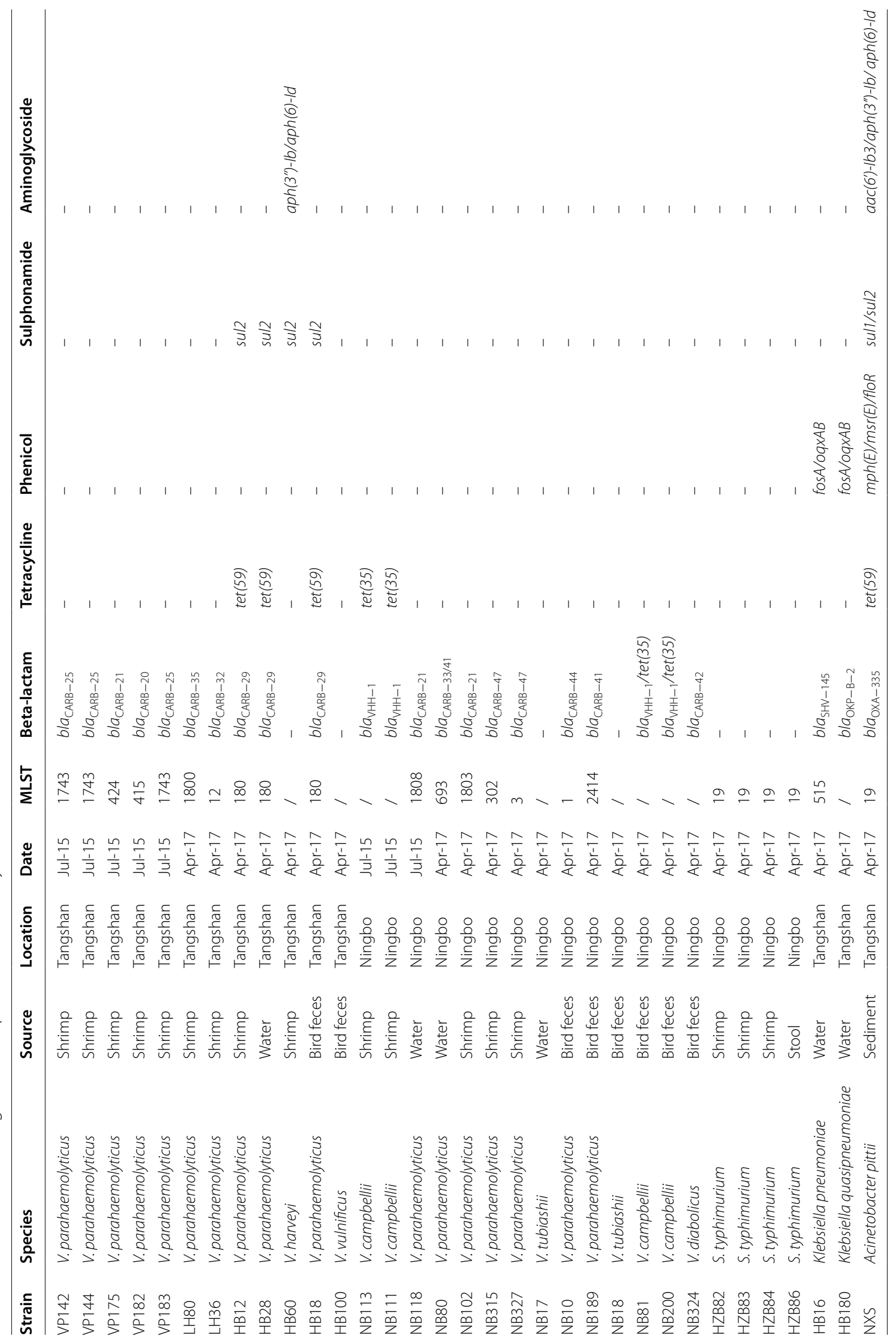




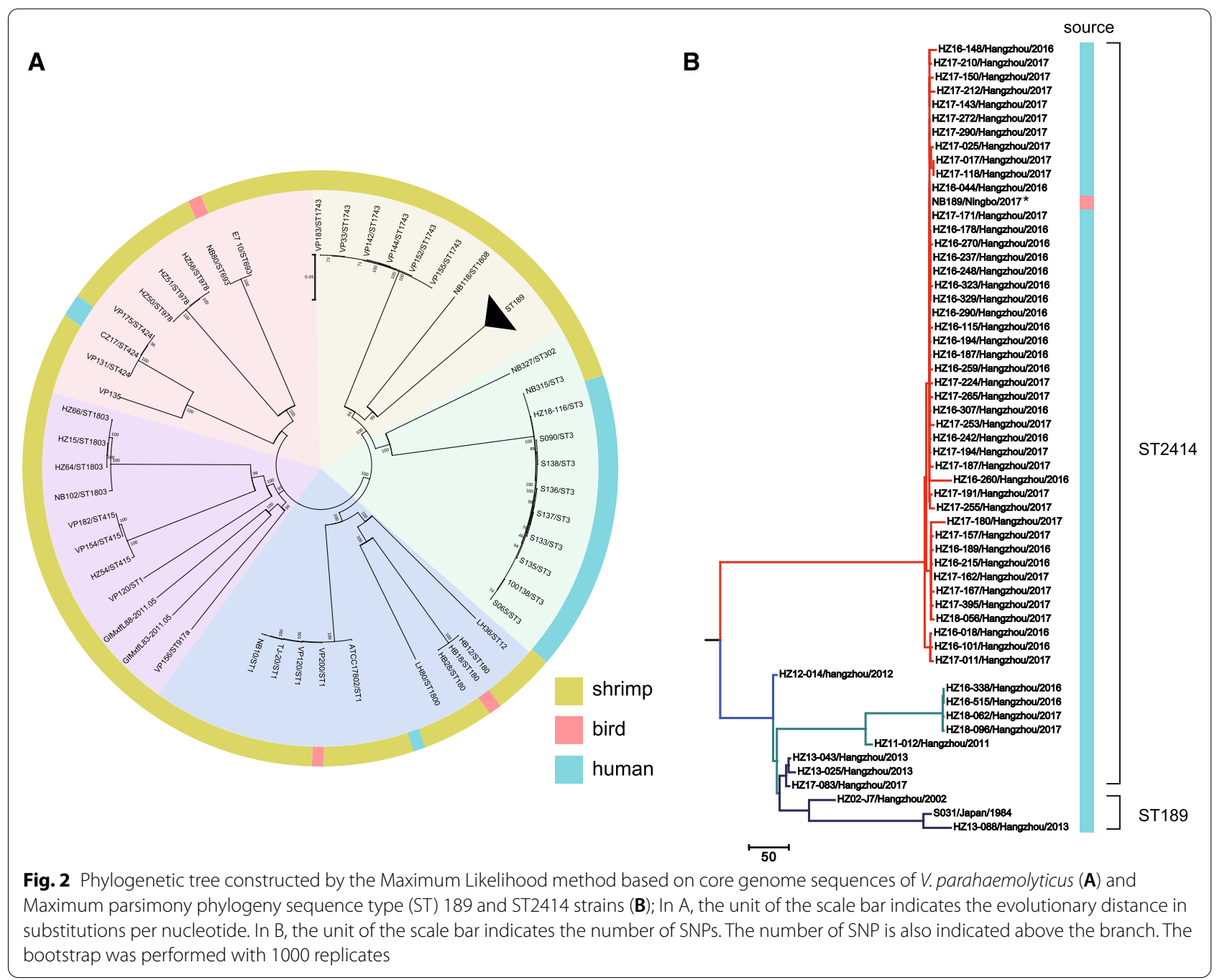

our primary analysis showed that three strains belonged to Cluster I of $V$. vulnificus, as defined by López-Pérez et al. [23]. Further genomic analysis of the Cluster I genomes revealed four lineages, of which the bird-carried $V$. vulnificus isolate $\mathrm{HB} 100$ was clustered with strain 93U204 and belonged to Lineage I (Fig. 3C).

\section{Identification and genomic epidemiology of other enteric pathogens in CFD and HZB}

In 2015, no enteric pathogens were detected in CFD farming region. However, one Klebsiella pneumoniae isolate HB16 and one Klebsiella quasipneumoniae isolate HB180 were identified in the waters of 2017. In HZB, three Salmonella typhimurium strains, designated HZB82, HZB83, HZB84, were isolated from the shrimp in 2017, respectively. MLST showed they all belonged to ST19. Shigella spp., and diarrheagenic E. coli were not isolated in any of samples.
To delineate whether K. pneumoniae isolate HB16 was associated with clinical samples, we additionally included $98 \mathrm{~K}$. pneumoniae public genomes (including 16 predominant STs in China, such as ST11, ST32 and ST35) [24] and performed a phylogenetic analysis based on the whole genome SNPs. The SNP alignment of the $99 \mathrm{~K}$. pneumoniae strains showed 170,269 SNPs. The phylogenetic analysis of $K$. pneumoniae revealed that isolate HB16 was not genomically related to any other Chinese clinical strains (Fig. 4A).

We further investigated whether three shrimp-originated $S$. typhimurium isolates were genomically related to any local clinical strains reported previously. Out of 29 local Salmonella strains isolated between 2016 and 2017 in Ningbo hospitals (Additional file 1: Table S4), one ST19 S. typhimurium isolate, designated HZB86 was picked up for whole-genome sequencing. Next, we combined 75 publicly available $S$. Typhimurium strains (Additional file 1: Table S5) with the four sequenced isolates 


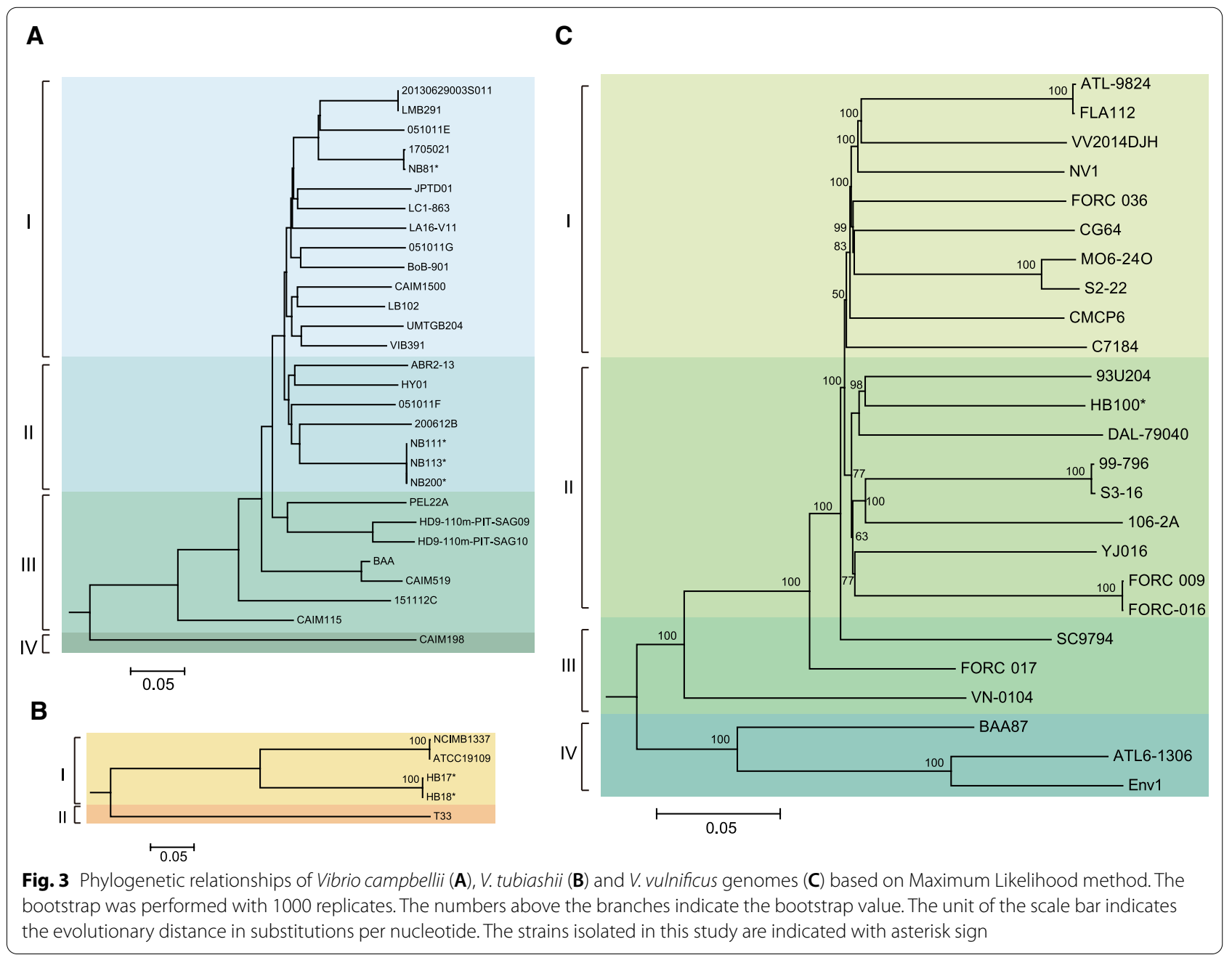

and constructed a minimum-evolution phylogenetic tree. The results showed that HZB82, HZB83, HZB84 were clustered with the local clinical strain HZB86, with maximum difference of five SNPs, indicating that these strains belonged to the same clone with epidemiological links (Fig. 4B).

\section{Comparison of bacterial community composition in the sediments between 2015 and 2017 in CFD farming region}

Bacterial Operational Taxonomic Units (OTUs) identified from the water in the CFD consisted of 55 phyla and 780 genera in 2015 (Additional file 1: Table S5). In 2017, bacterial OTUs constituted 51 phyla, and 630 genera. In terms of bacterial diversity, the Shannon indices decreased significantly $(p<0.05)$ (i.e., from $7.1 \pm 0.2$ in 2015 to $6.7 \pm 0.2$ in 2017) (Table 2). The number of observed species dropped from $1288 \pm 44$ in 2015 to $1189 \pm 94$ in 2017. Simpson Diversity indices decreased from $0.98 \pm 0.005$ in 2015 to $0.97 \pm 0.004$ in
2017 with a significant difference $(p<0.05)$. The Chao 1 index decreased from $1457 \pm 38$ in 2015 to $1422 \pm 206$ in 2017, but the differences were not significant $(p>0.05)$.

Proteobacteria was the dominant phylum in the wetland both in 2015 and 2017 (Fig. 5A). Typical genera included Limonohabitant, Actinobacteria, Cyanobacteria, Malikia, Candidatus Methylopumilus and Sediminibacterium (Fig. 5B).

With respect to the relative abundance at genus level, there were significant differences $(p<0.05)$ at the genus level between 2015 and 2017 (Fig. 5B). The relative abundance of Malikia and Limnohabitans increased significantly $(p<0.05)$ in 2017. Meanwhile, the decrease of Acinetobacter and Cyanobacteria were observed in the sediment samples from 2017. In 2015, weighted UniFrac distance-based PCoA plots showed that the microbial composition in location A of CFD was similar to locations B and C. However, samples in location A were different in 2017, suggesting that the chemical composition 
A

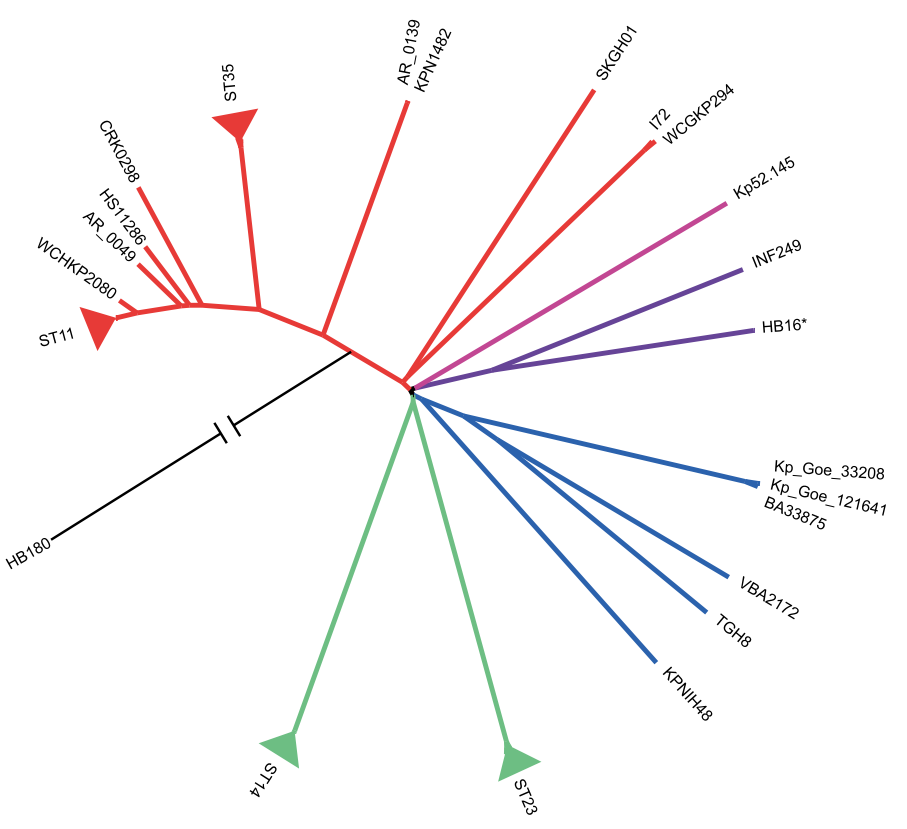

$\overline{0.009}$

B

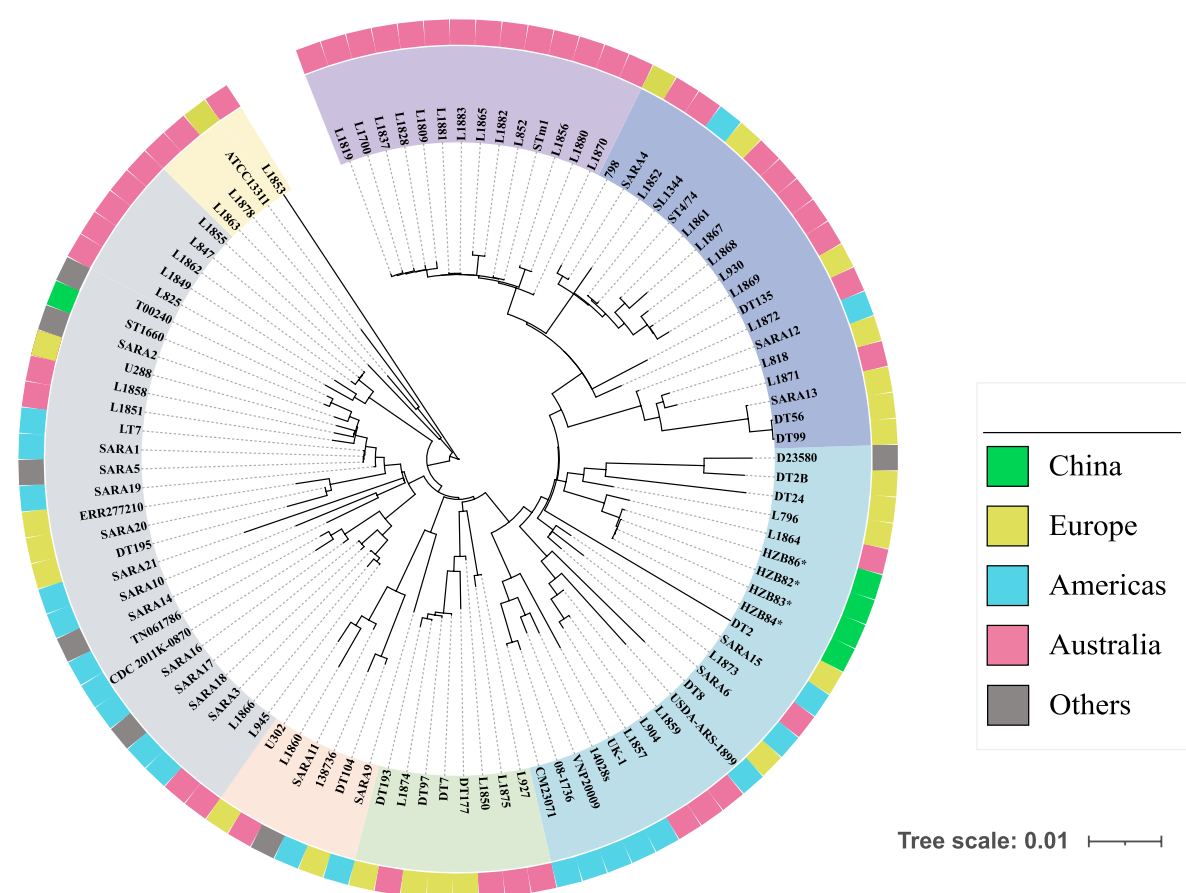

Fig. 4 Phylogenetic tree constructed by the Maximum Likelihood method based on core genome sequences of Klebsiella pneumoniae (A) and Salmonella typhimurium (B). Genomes come from China, Europe, Americas, Australia and other countries are highlighted in green, brown, blue, pink, and gray, respectively. The unit of the scale bar indicates the evolutionary distance in substitutions per nucleotide. The bootstrap was performed with 1000 replicates. The strains isolated in this study are indicated with asterisk sign 
Table 2 Diversity index of microbial community CFD and HZB in 2015 and 2017

\begin{tabular}{|c|c|c|c|c|c|c|}
\hline \multirow[t]{2}{*}{ Index } & \multicolumn{2}{|l|}{ CFD } & \multirow[b]{2}{*}{$P$ value } & \multicolumn{2}{|l|}{ HZB } & \multirow[b]{2}{*}{$P$ value } \\
\hline & 2015 & 2017 & & 2015 & 2017 & \\
\hline No. of species & $1288 \pm 44$ & $1189 \pm 93$ & 0.182 & $1276 \pm 71$ & $1237 \pm 53$ & 0.488 \\
\hline Shannon & $7.11 \pm 0.21$ & $6.67 \pm 0.16$ & $0.045^{*}$ & $5.24 \pm 0.3$ & $4.84 \pm 0.3$ & 0.178 \\
\hline Simpson & $0.979 \pm 0.0046$ & $0.968 \pm 0.004$ & $0.035^{*}$ & $0.789 \pm 0.015$ & $0.854 \pm 0.018$ & $0.009^{* *}$ \\
\hline Chao1 & $1457.4 \pm 41.9$ & $1422.3 \pm 205.5$ & 0.784 & $1023.4 \pm 31$ & $1044.4 \pm 151$ & 0.825 \\
\hline
\end{tabular}

CFD: Caofeidian district; HZB: Hangzhou bay district; * and ** indicate significant differences at $\mathrm{P}<0.05$, and 0.01 levels, respectively,
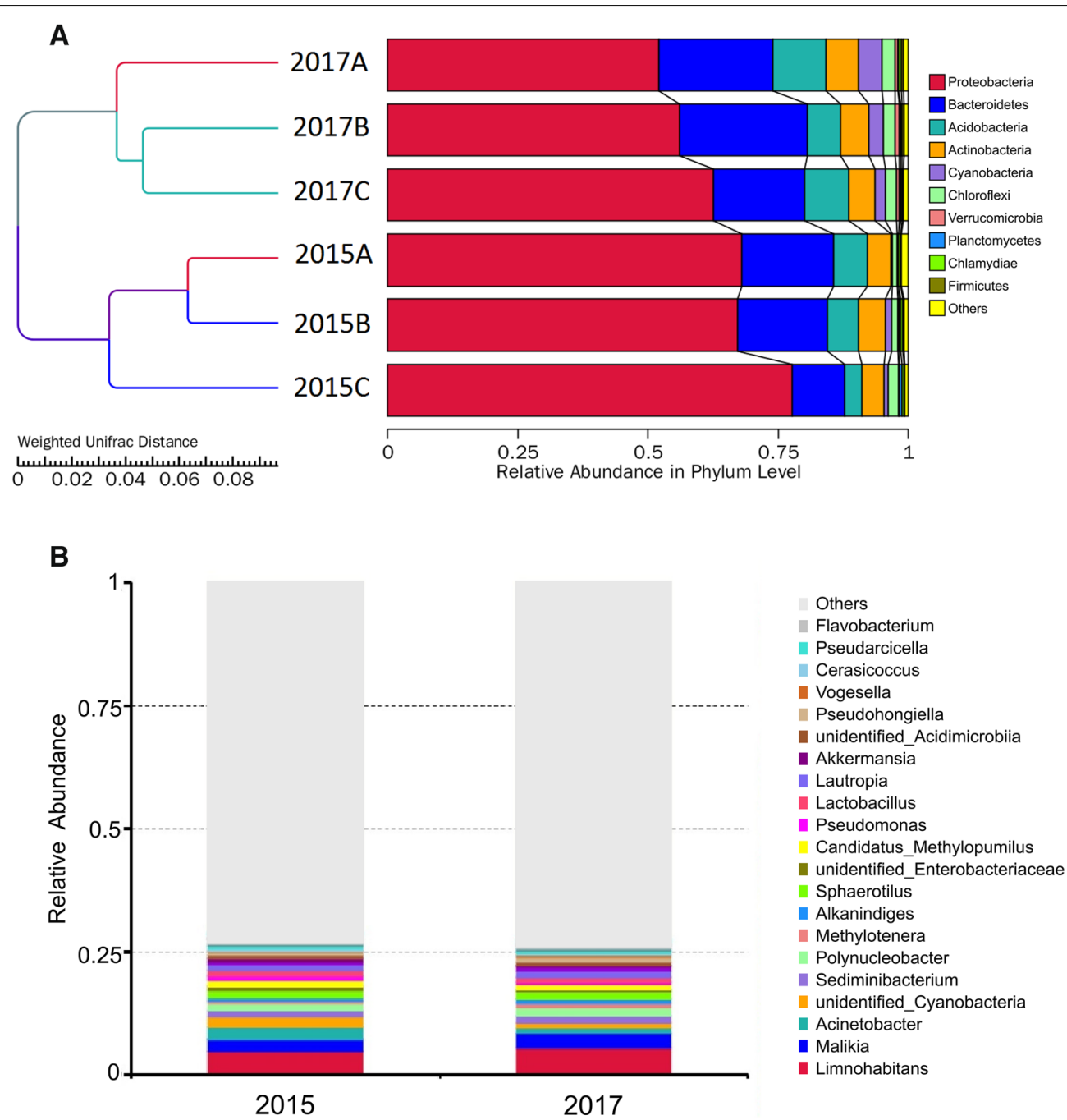

Fig. 5 Relative abundance of bacterial communities in the sediment from shrimp pond in Caofeidian at the phylum level in 2015 and 2017 (A). Phylogenetic relationships and relative abundance of top 20 bacterial genus in the CFD wetland (B)

of the sediment is affected by surrounding shrimp ponds, resulting in microbial composition changes.

Functional prediction analysis of the bacterial communities showed that bacterial functional groups underwent drastic changes attributed to shrimp farming activities
(Additional file 2: Figure S2). Before shrimp farming, the functions of bacteria were mainly associated with aromatic compound degradation, animal parasites, sulfur reduction and chemoheterotrophy. In contrast, after shrimp farming activities have taken place, sediments 
had higher levels of predicted functions involved in methanol oxidation, the nitrogen cycle and carbon compound degradation. Methanol oxidation was attributed to the core OTUs affiliated with Arthrobacter, and methylotrophy with Methylobacterium OTUs, according to the FAPROTAX database. Nitrogen respiration was associated with numerous organisms, such as Paracoccus and Pseudomonas, while carbon compound degradation was associated with many bacterial species.

\section{Dynamics of bacterial community composition} in the sediments between 2015 and 2017 in the HZB farming region

Overall, from HZB water samples in 2015 and 2017 revealed 375 and 330 genera, respectively (Table 2). Simpson index in 2017 samples is significant higher than the one from 2015 samples $(p<0.05)$. Proteobacteria was the most abundant bacterial phylum in all three sampling sites, with an average relative abundance of $75.5 \% \pm 0.1$ in 2015 and $80.9 \% \pm 0.3$ in 2017, respectively (Fig. 6A). The next two most abundant phyla were Bacteroidetes with $15.2 \% \pm 0.5$ and $7.6 \% \pm 0.1$ in 2015 and 2017, and Actinobacteria with $5.0 \% \pm 0.5$ and $3.5 \% \pm 0.3$ in 2015 and 2017, respectively. Regarding the bacterial composition at the genus level, the top three genera with the highest relative abundance were Vibrio with $36.3 \% \pm 0.2$, Flavobacterium with $7.0 \% \pm 0.4$, and Lentibacter with $4.3 \% \pm 0.1$ in 2015 , and $45.2 \% \pm 0.7,2.2 \% \pm 0.40$ and $2.1 \% \pm 0.4$ in 2017, respectively (Fig. 6B). Potential bacterial pathogens including Mycobacterium sp., Vibrio sp. and Salmonella sp. were identified.

Functional prediction analysis of the bacterial communities revealed that there was significant difference between the samples from 2015 to 2017 (Additional file 2: Figure S3). The number of cyanobacteria and its associated function prototrophy significantly increased in 2017, indicating water eutrophication in the farming region.

A
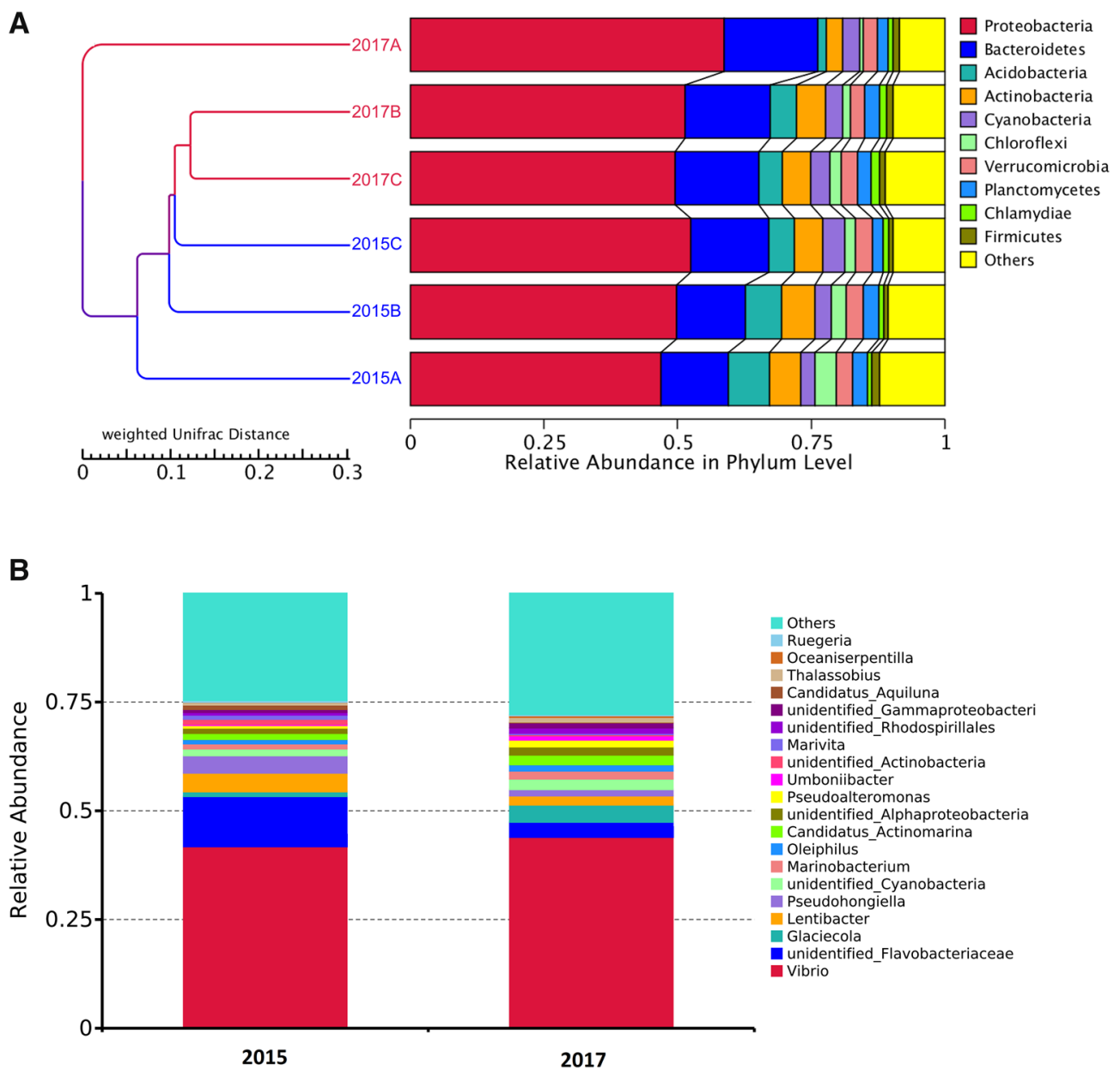

Fig. 6 Relative abundance of bacterial communities in the sediments from shrimp ponds in Hangzhou Bay at the phylum level in 2015 and 2017 (A). Phylogenetic relationships and relative abundance of top 20 bacterial genus in the HZB district (B) 
In $\mathrm{HZB}, \mathrm{PCoA}$ revealed that there is no significant difference among three sampling sites in 2015 (Additional file 2: Figure S1B). Intriguingly, in 2017, while the microbiota in sampling sites $B$ and $C$ remained comparable to the 2015 counterparts, a distinctive difference in the microbial communities could be observed between 2015 and $2017 \mathrm{~A}$.

\section{Re-isolation of human pathogens from the sediments}

Apart from successful culturing of Vibrio spp. and Salmonella spp. isolates, our metagenomics analysis had also detected the increased abundances of several potential human pathogens among the 2017 sediment samples, including Acinetobacter sp. and Legionella sp. in CFD, and Mycobacterium sp. in HZB. To confirm the presence of human pathogens at species level, disaggregated sediments were spread onto corresponding enrichment medium. Acinetobacter pittii, Acinetobacter junii, Mycobacterium vaccae and Legionella dumoffii were isolated from the sediments in 2017 but not in 2015. As A. pittii is recognized increasingly as a clinically important species, one $A$. pittii isolate NXS obtained in this study was further sequenced. Together with 125 public genomes and six previously sequenced $A$. pittii genomes (AP4, AP5, AP11, AP15, AP17 and HB181) from Liaoning provinces [9] (Additional file 1: Table S8), phylogenomic analysis revealed that $A$. pittii isolate from sediment was clonally related with another strain HB181 obtained from the ventilator of a hospital (Additional file 2: Figure S4).

\section{Antimicrobial resistance of the isolates}

Overall, the Vibrio strains isolated from bird feces and aquatic animals showed similar antibiotic resistance profiles (Additional file 1: Table S1). The prevalence of antimicrobial resistance genes analyzed using ResFinder showed that all $V$. parahaemolyticus isolates carried intrinsic resistance to beta-lactams and three ST180 isolates harbored tet(59) and sul2 additionally. Accordingly, a disc diffusion experiment revealed that all $V$. parahaemolyticus strains showed resistance to amoxicillin, of which ST180 isolates were also resistant to tetracycline and sulfadiazine. In addition, another bird-carried $V$. diabolicus strain harbored $b l a_{\mathrm{CARB}-42}$ and was resistant to amoxicillin. Antimicrobial resistance genes were not identified in two $V$. tubiashii strains, and they also displayed no resistance to any of the tested antibiotics. Genomic analysis confirmed that all sequenced V. campbellii strains carried bla $_{\mathrm{VHH}-1}$ and tet(35).

The $K$. pneumoniae strain HB16, which harbored blaSHV-145/fosA/oqxAB, showed resistance to betalactam, aminoglycoside, phenicol, sulphonamide, and macrolide. Genomic analysis of the $K$. quasipneumoniae strain HB180 showed the presence of blaOKP-B-2, fos $A$ and $o$ q $x A B$ genes, which encode for beta-lactam resistance, fosfomycin resistance, and quinolone resistance, respectively.

Notably, A. pittii isolates NXS and HB181 were resistant to nine out of 10 drugs tested in this study (Additional file 1: Table S1). A genomic analysis showed that both strains carried 10 antimicrobial resistance genes, including $b l a_{\mathrm{OXA}-335}$ (encoding for Beta-lactam resistance), $a a c$ (6')-Ib3, $a p h\left(3^{\prime \prime}\right)-I b$ and $a p h(6)$-Id (encoding for Aminoglycoside resistance), floR (Phenicol resistance), sul1/sul2 (Sulphonamide resistance), $m p h(\mathrm{E})$ and $m s r(\mathrm{E})$ (encoding for Macrolide resistance), and tet(59).

\section{Discussion}

One health genomic surveillance demonstrated the epidemiological links between enteric pathogens in environment and communities

Although it has been well recognized that wetlands have important functions in flood conveyance, groundwater recharge, shoreline erosion control, and water storage [6], the impacts of intensive farming within wetlands on the spillover of pathogens during this process have been neglected. The CFD and HZB wetlands experienced typical human ecological problems with regard to the relationship between the ecosystem and the socio-economic system: fast aquaculture development in a non-sustainable manner for short-term economic gains. Coastal areas often face such a dilemma between economic development and environmental interests in developing countries, most of which result in a lose-lose situation.

Investigation on the dynamics of microbial communities during the human-driven land conversion is the key for illustrating pathogen spillover and seasonal epidemics [25]. For instance, in Malaysia, intensification of pig farming adjacent to bat-attracting mango plantations resulted in the emergence of Nipah virus in pig populations, due to the pig consumption of mango eaten by bats [26]. Failure to acknowledge the life-support function of mangroves was one explanation for the boom-and-bust outbreak of shrimp disease [27]. There are roughly 35,000 hectare of abandoned shrimp ponds in the Mekong Delta, of which about 50\% may be rehabilitated [28]. In Thailand, $70 \%$ of previously productive ponds have been abandoned [29]. However, few studies confirmed the direct epidemiological links of enteric pathogens between agriculture environment and local communities [30]. In this study, comparative genomic analysis of Vibrio spp. obtained from shrimp and local clinical samples confirmed such a transmission chain. Phylogenetic genome comparisons demonstrated that ST3 and ST2414 Vibrio parahaemolyticus isolates obtained from aquatic animals were clonally related to patient isolates. Chen et al. [31] demonstrated that V. parahaemolyticus ST302 
isolates were clustered with other pandemic serotype O3: K6 isolates based on enterobacterial repetitive intergenic consensus sequence PCR (ERIC-PCR), suggesting that ST302 was likely to be serovariants of ST3. However, our study confirmed that ST302 was not genomically related to ST3 as they differ by over 5000 SNPs.

Likewise, three Salmonella Typhimurium isolates were also genomically related to one clinical strain. These results suggested that high-density shrimp farming would cause the high prevalence of potentially enteric pathogens in farms, which might eventually result in human infections via consumption of contaminated seafood. In contrast, environmental and patient Klebsiella isolates were genetically distinct, suggesting that Klebsiella causing serious human infection did not directly originate from aquatic farms.

Sediment can be a potential reservoir of microbe due to their protective and nutrient-rich environments [32]. Thus, bacterial communities in sediments also can be used as indicators to reflect the impacts of intensive farming on pathogen spillover. Sousa et al., (2006) investigated the impacts of shrimp farming effluent on the bacterial communities in mangrove waters and found that pathogenic Vibrio spp. were introduced in the mangrove [33]. In this study, the investigated wetlands underwent dramatic land use changes, from a wetland to a shrimp monoculture land use system in a very short time span. Our results showed that farming activities significantly changed the bacterial community composition in the sediments, and resulted in the emergence of several pathogens. Likewise, in this study, the distinct microbial communities in the CFD farming region between 2015 and 2017 revealed the emergence and increasing of several pathogens, such as Acinetobacter and Legionella. Dynamics of bacterial community composition in the HZB farming region suggested that Vibrio has become a predominant genus in the sediments. Interestingly, the HZB and CFD farming regions showed a remarkably different bacterial community composition, which might be associated with the salinity, oil contamination, the land type and duration of the farming activity. The CFD farming region is far from the coast and has an average salinity of $2.3 \mathrm{ppt}$. The coastal wetland was recently converted into shrimp ponds in 2015, which explained the similarity of bacterial composition in 2015. At that time, Proteobacteria was the dominant phylum. Its sediment suffered previous oil contamination, explaining the abundance of Alkanindiges and other genera related to oil degradation. The abundances of several genera associated with shrimp farming were also increased in 2017, such as Lactobacillus, Pseudomonas and Acinetobacter.

In contrast to CFD, the HZB farming region is close to the sea shore and is strongly affected by the tide, with an average salinity of $8.5 \mathrm{ppt}$. The surrounding areas of sampling sites $\mathrm{A}, \mathrm{B}$ and $\mathrm{C}$ were used for aquaculture activities since a decade ago. This long term shrimp farming has caused the profound alteration on the microbial community structure, resulting in similar microbiota profiles in 2015 as shown by a PcoA plot (Additional file 2: Figure S1B). Notably, the microbiota in sample 2017 A was remarkably different compared to its 2015 counterpart. The cause of the remarkable microbiota difference seen in 2017 A requires further investigation.

Field studies have shown that the conversion of coastal bulrush wetland to aquaculture pond enhanced total microbial biomass in sediment and increased the abundance of various bacterial species, many of which were human pathogens [34]. However, it has been suggested that levels of dissolved nutrients are always kept low because they are consumed by microbiota in the matured water, maintaining the stability of the microbial community and the competition between bacteria [35]. The surge of pathogenic Vibrio spp. in shrimp farming is mainly associated with high nutrient levels which promote the growth of fast-growing pathogens. Although it is currently unknown how the biogeochemical processes in the wetland influence the detail dynamics of bacterial community structure, our study is a first step toward understanding how the shrimp farming impacted the eco-health in the wetlands.

\section{Genomic analysis confirmed the dissemination of pathogenic Vibrio spp. among water birds and shrimp} Apart from the transmission from the farm to local communities via consumption of shrimp [16], transmission of pathogenic Vibrio spp. can also occur through water birds. Halpern et al. [36] suggested that the dispersal of Vibrio spp. by water birds might be attributable to their direct predation of chironomids and copepods. Pretzer et al. [37] revealed that bird migration explained the high genetic diversity of $V$. cholerae isolates in a European lake (Lake Neusiedl). Our previous studies also found that bird-carried Vibrio strains in water birds could be acquired through the direct predation of local mollusks [21]. However, very little is known about whether the conversion of wetlands to farms may accelerate the dissemination of pathogens. Our results showed that many Vibrio strains isolated from shrimp farms were clonally related to strains found in bird feces as well as local clinical samples. Therefore, the conversion of wetlands into aquaculture farms may result in pathogen spillover from aquatic animals to local communities and wild birds.

Using high-resolution genomic typing, we also determined the precise origins of the Vibrio spp. isolated from birds at two coastal farming regions in China. As a large number of wetlands have been converted to aquaculture 
farms, migratory birds now have to predate aquatic animals as an alternative food source. Previous field investigation also showed that in the Tangshan CFD district, the sampled shrimp and fish ponds suffered from large-scale predation by water birds, resulting in a loss of farmed animals during the bird migration season [38]. However, the high bacterial density of aquaculture ponds often leads to a high pathogen load and antibiotic resistance, and such predation behaviors are expected to enhance the acquisition of pathogens and facilitate cross-species transmission. On the other hand, altered migration routes may also facilitate contact between otherwise geographically separated host species, leading to the introductions of novel and unexpected pathogens and increasing health risks for humans. One example of this phenomenon involves outbreaks of $\mathrm{H} 5 \mathrm{~N} 1$ avian flu, which is associated with recombination that occurred within wild birds [39].

Meanwhile, the predation of water birds from aquatic farms causes another issue: the acquisition of antibiotic resistance. The overuse of antibiotics in aquaculture has been well documented in recent years, which is associated with the development of multi-drug resistance [40]. The multi-drug resistance is likely transferred by water birds along the migration route. In this study, several multi-drug resistant pathogens were isolated from the water birds inhabited stopover sites. These findings underscore that the aquacultural activity near nature reservoirs may greatly promote the spread of antibiotic resistance genes.

Owing to their long-distance movement and exposure to diverse habitats, migratory animals have far-reaching implications for the emergence and spread of infectious diseases [41]. Apart from pathogenic Vibrio spp. in water birds, contemporary studies have uncovered that migratory species harbor zoonotic pathogens of importance to humans, such as avian influenza viruses in water birds [42] and West Nile virus (WNV) in songbirds [43]. These studies illustrate the profound ecological and infectious consequences of migratory animals to pathogen transmission on a local scale. Therefore, restoring the food sources in wetlands is urgently needed to prevent future risks to human health.

Our study has three limitations. First, although several epidemiological links have established between animal and clinical isolates, within the limitations of sampling, we might not able to obtain all of the environmental genotypes of enteric bacterial pathogens. Thus, epidemiological links among farming region, water birds and local communities might be underestimated. Another limitation is that pathogens from other sources such as wastewater contamination from other types of food or recreational waters might also result in human infection. Thus, isolation of pathogen from other sources such as livestock would lead to better understanding on the sources of all human infections. Additional studies are required to understand whether our findings can be reproduced in other geographical areas. Thirdly, only two out of three sampling points became shrimp ponds during the study period, thus, this study lacks of sufficient sampling points to understand how the conversion of wetlands into aquaculture farms influence the detailed dynamics of bacterial community structure. Therefore, to what extent, this conversion resulted in pathogen spillover from aquatic animals to local communities and wild birds remains unknown. Nevertheless, our study is a first step towards understanding the impact of shrimp farming activities on the eco-health, highlighting an urgent need to protect the nature reserves. Future studies using metagenomic sequencing may help to determine how sustainable shrimp farming practices can improve the bacterial community structures that are variable among different wetlands.

\section{Conclusions}

Our results clearly suggest that several problems experienced in the CFD and HZB wetlands should be urgently addressed. Comparative genomic analysis of pathogenic Vibrio spp. isolates obtained from wetlands, shrimp farms and local communities confirmed the dissemination of pathogens among wild birds, aquatic animals and humans. These findings confirm that pathogens can be transmitted from shrimp farms to migratory birds and the environment in estuaries, which underscores the impact of wetland destruction on the transmission of pathogens and antibiotic resistance. From a One Health perspective, the expansion of aquaculture farms near nature reservoirs must be re-evaluated. To prevent the rapid spread of pathogens, proper management actions to ensure a sustainable growth and benefit of shrimp cultivation should be adopted.

\section{Materials and methods \\ Study area}

Two coastal regions, CFD (118.46 E, 39.27 N) and HZB $(121.17 \mathrm{E}, 30.32 \mathrm{~N})$ were selected for field investigation which used to be wetlands in 2015 (Fig. 1).

CFD farming region is located in the intersection of the river, the lake and the sea in Caofeidian district of Tangshan with 54,000 hectares. This region owns more than 307 types of waterbirds. There are over 50,000 waterbirds would stopover at this wetland during the spring. Since 2010 , it has been surrounded by a large area of aquaculture ponds, occupying over $90 \%$ of the original wetland and were used mainly for shrimp or fish farming activities. Due to the expansion of aquaculture, many waterbirds roost in aquaculture ponds to seek food. 
HZB farming region is located near the southern end of the Hangzhou Bay Bridge in the suburbs of Ningbo with 41,400 hectares. The park contains open shoals, giant reeds and wild grasses. It has vast intertidal flats (extending 3-5 km at low spring tides). The activities of water birds are strongly affected by the tide, which usually forages on the intertidal flats at low tide and rest in the hightide roosts at high tide.

All sampled wetlands suffered from severe deterioration (Fig. 1). HZB wetland in Ningbo has been surrounded by a large area of aquaculture ponds along the coastline, which occupied more than $90 \%$ of the wetland. In 2017, field investigation showed that the core region of the wetland in Hangzhou Bay shrunk to only 300 hectares. Aquaculture ponds adjacent to the high-tide roosts are mainly used for the farming of fish and shrimp. In CFD farming region, field investigation showed that all the sampled shrimp farms located within the original wetland, of which shrimp farms and fish farms occupied $95 \%$ of water surface of the original wetland. Antibiotics, such as florfenicol, fluoroquinolone, sulfonamide, and tetracycline were widely used for the treatment of shrimp/fish disease in these farms.

\section{Sampling of water, shrimp and bird feces in the CFD and HZB}

Two rounds of sampling were conducted in two coastal regions in July-2015 and April-2017, respectively. Sampling was selected at three angle points in wetlands, of which two points became shrimp pond in 2017 in both regions (Fig. 1). Two liters of water were collected from $1 \mathrm{~m}$ beneath the surface. Meanwhile, 15 sediment samples (each with $100 \mathrm{~g}$ ) were collected both from the bottom of shrimp pond and wetland lake in two regions. Besides, 20 shrimp samples (Penaeus vannamei) with average individual weight of $12 \pm 3.4 \mathrm{~g}$ were sampled from each pond.

To evaluate the pathogen spillover from shrimp to water birds, in April-2017, 30 samples of fresh bird feces were collected near the sampled shrimp ponds. Sampled bird feces came from Ruddy Shelduck (Tadorna ferruginea), Oriental White Stork (Ciconia boyciana), Common Greenshank (Tringa nebularia), Spoon-billed Sandpiper (Eurynorhynchus pygmeus), Eurasian curlew (Numenius arquata), Far Eastern Curlew (Numenius madagascariensis), and Black-tailed godwit (Limosa limosa). Fresh droppings were collected when only a single species presents based on field surveys. Droppings from the same species were mixed to give sufficient availability samples consisted of $10 \mathrm{~g}$. All samples were placed in sterile containers and transported to the laboratory via ice package within $8 \mathrm{~h}$.
Isolation and identification of bacterial enteric pathogens from shrimp, water and bird fecal samples

Five typical bacterial enteric pathogens (pathogenic Vibrio spp., Shigella spp., Salmonella spp., diarrheagenic E. coli, and Klebsiella spp.) were selected for One Health surveillance.

Briefly, for pathogenic Vibrio spp., ten grams of sampled shrimp or bird feces were aseptically homogenized with a blender for $5 \mathrm{~min}$ in $100 \mathrm{ml}$ alkaline peptone water (peptone, $10 \mathrm{~g}$ per L; sodium chloride, $10 \mathrm{~g}$ per L) and pre-cultured at $28{ }^{\circ} \mathrm{C}$ for $8-12 \mathrm{~h}$. Subsequently, $100 \mu \mathrm{l}$ of culture was spread on thiosulfate citrate bile salts sucrose (TCBS) agar plates (Hopebio, Qingdao, China) and incubated at $28{ }^{\circ} \mathrm{C}$ for $24 \mathrm{~h}$ as described previously [44]. Individual green or yellow colonies were identified and sub-cultured in tryptic soy agar plates (TSA) and incubated at $28{ }^{\circ} \mathrm{C}$ for $24 \mathrm{~h}$ to obtain pure isolates.

Meanwhile, the following enrichment media (Hopebio, Qingdao, China) were also used, including Shigella broth for Shigiella spp., tetrathionate broth with iodine and brilliant green for Salmonella spp., and mEC broth for diarrheagenic E. coli. Following pre-incubation at $37{ }^{\circ} \mathrm{C}$ for $48 \mathrm{~h}, 0.1 \mathrm{ml}$ of bacterial suspension was plated onto MacConkey agar plate and incubated further for $24 \mathrm{~h}$ at $37^{\circ} \mathrm{C}$. For bacterial identification, isolates were subjected to PCR amplification of $16 \mathrm{~S}$ rRNA genes with the bacterial universal primers (27 F/1492R) [45]. The amplicon was sequenced by ABI 3730 DNA Analyzer (Applied Biosystems, Foster City, CA) in Jingtong Biotech Co., Ltd. (Shanghai, China). The similarity of the 16S rRNA gene sequence was examined by using the BLASTn program in NCBI (https://blast.ncbi.nlm.nih.gov/Blast.cgi).

\section{Genome sequencing and gene content analysis}

Genomic DNA was extracted from overnight cultures grown in tryptic soy broth supplemented with $1.5 \%$ $\mathrm{NaCl}$ (TSB15) by using bacterial genomic DNA extraction kit (TIANGEN, Beijing, China). The DNAs were indexed with a Nextera XT DNA Sample Preparation kit and sequenced on the Illumina MiSeq platform with the paired-end $2 \times 300$ bp protocol at Novogene (Tianjin). For the FASTQ reads, bases with a PHRED score of $<30$ were removed from the trailing end by Trimmomatic (v0.36) [46]. The draft genomes were assembled de novo with SPAdes (v3.0) [47]. The genomes were annotated by RAST server [48]. In silico multilocus sequence typing (MLST) of $V$. parahaemolyticus and $V$. vulnificus was performed with the MLST 2.0 server (https://cge.cbs.dtu. $\mathrm{dk} / /$ services/MLST/2 at the Center for Genomic Epidemiology [49]. Antimicrobial resistance genes were identified with ResFinder [50]. 
Identification of SNPs and phylogenetic inferences For pathogenic Vibrio spp., the reference genomes 20130629003S011, ATCC19109, FORC_017 and RIMD2210633 were used to call the single nucleotide polymorphism (SNP) for $V$. campbellii, V. tubiashii, $V$. vulnificus and $V$. parahaemolyticus, respectively. The assemblies of Salmonella enterica and Klebsiella pneumoniae isolates were aligned to the $S$. Typhimurium LT2 genome (NC_003197) and K. pneumoniae genome (NC_003197) by BWA v0.7.12, respectively [51]. The SNP data used for phylogenetic analysis were identified using the SnpFilt tool [52]. The phylogenetic trees were constructed with the maximum likelihood method using RAxML 7.2.8 [53]. The generalized time reversible (GTR) with gamma rates (G) and invariant sites (I) $(G T R+G+I)$ model was used. For closely related strains, the maximum parsimony algorithm was used to precisely identify the SNPs that differed among them, in PAUP 4.0 [54].

\section{Antibiotic resistance profiles}

Antimicrobial susceptibility testing was carried out by using a disk diffusion assay of 10 antibiotics (Additional file 1: Table S1). The test was performed by employing a bacterial inoculum of approximately $1-2 \times 10^{8}$ $\mathrm{CFU} \cdot \mathrm{mL}^{-1}$ to the surface of Mueller Hinton agar plate. The plates were incubated for $24 \mathrm{~h}$ at $28{ }^{\circ} \mathrm{C}$ and the inhibition halo around each antibiotic disc was measured using a vernier caliper. Breakpoints of the antibiotics were interpreted using the criteria published by the Clinical and Laboratory Standards Institute [55].

\section{S rRNA gene sequencing and analysis of the sediment samples}

To analyze the dynamics of microbial composition in the sediment before and after the shrimp farming in the CFD and HZB farming region, we also sampled the sediments from two shrimp ponds and one wetland lake for $16 \mathrm{~S}$ rRNA sequencing and analysis. Sediment DNA was extracted using the Mo Bio Power soil DNA isolation kit (MO BIO Laboratories, Inc., Carlsbad, CA) following the manufacturer's protocol. The barcoded primer set (515 F/806R) targeting the V4 hypervariable region of the 16S rRNA gene was used for PCR amplification. Subsequently, PCR products were purified using Ampure $\mathrm{XP}$ beads according to the manufacturer's instructions, followed by multiplexing and sequencing on an Illumina MiSeq platform with the paired-end $2 \times 300$ bp protocol at Novogenes (Tianjin).

The raw fastq files were processed by UPARSE pipeline as described by [56]. Then, the operational taxonomic units (OTUs) were assigned using UPARSE at a
97\% sequence identity [57]. RDP classifier v2.12 [58] and SILVA database v123 implemented in QIIME (v1.6.0) [59] were used to assign taxonomy to representative sequences of each OTU with default parameters. Functional prediction of the sediment bacterial communities was performed using Functional Annotation of Prokaryotic Taxa v.1.0 (FAPROTAX) [60]. Additionally, alpha diversities (species richness, Chao1, Shannon and Simpson indices) and beta diversities (weighted Unifrac and Bray-Curtis metrics) were analysed using QIIME [61]. Weighted UniFrac distances matrix at OTU level was calculated in R by using UniFrac function [62]. PCoA was conducted to visualize relationships of bacterial composition in the sediment before and after shrimp farming.

\section{Isolation of the pathogens from the sediments}

Twenty-five grams of sampled sediments were aseptically disaggregated in $0.9 \%$ saline water. Subsequently, 1 $\mathrm{ml}$ of suspension was spread onto TSA or buffered charcoal yeast extract (BCYE) agar. Suspected Legionella colonies were further isolated on BCYE agar [63]. Acinetobacter spp. was isolated using the chromogenic HiCrome Acinetobacter Agar (HiMedia, India). Mycobacterium was isolated by Herrold's egg yolk medium as described by Makovcova et al. [64]. PCR amplification and Sanger sequencing of the $16 \mathrm{~S}$ rRNA gene was conducted as described above.

\section{Statistical analysis}

Statistical analyses were conducted using $\mathrm{R}$ package [62]. The analysis of similarity (ANOSIM) and permutational multivariate analysis of variance (PERMANOVA) were implemented in the $R$ package vegan to test the significance of the taxa differences between two microbial communities. The obtained profiles of KEGG pathways were further subjected to the software package Statistical Analysis of Metagenomic Profiles (STAMP) to confirm the pathway abundance differences [65]. For data following normal distribution, one-way Analysis of Variance (ANOVA) at a 5\% significance level was conducted followed by the post hoc analysis Tukey Honest Significant Test.

\section{Supplementary Information}

The online version contains supplementary material available at https://doi. org/10.1186/s13099-021-00442-4.

Additional file 1. Additional Tables.

Additional file 2. Additional Figures.

\section{Acknowledgements}

We thank for Mr. Xudong Shen and Ms Yisha Lu for sampling assistance. We acknowledge Dr. Yun Luo from Zhejiang Center for Disease Control and Prevention for providing clinical information and strains. 


\section{Authors' contributions}

Conceptualization: SF and QY; methodology: QW, YZ; validation: FS, QW and YZ; formal analysis: SF QY; investigation: QW, and YZ; resources: TD; writingoriginal draft preparation: SF and QY; writing, review and editing: TD, SF and QY; funding acquisition: SF and QY. All authors have read and agreed to the published version of the manuscript. All authors read and approved the final manuscript.

\section{Funding}

This research was supported by National Natural Science Foundation of China (81903372), Youth project from Educational Commission of Liaoning Province of China (QL202005) and the Special Research Fund of Ghent University (BOF-UGent).

\section{Availability of data and materials}

The raw sequencing data were submitted to GenBank under the BioProject No. PRJNA503785.

\section{Declarations}

Ethics approval and consent to participate

Not applicable.

\section{Consent for publication}

Not applicable.

\section{Competing interests}

The authors declare that they have no conflict of interest.

\section{Author details}

${ }^{1}$ College of Marine Science and Environment, Dalian Ocean University, No. 52 Heishijiao Street, Dalian 116023, China. ${ }^{2}$ Key Laboratory of Environment Controlled Aquaculture (KLECA), Ministry of Education, 116023 Dalian, China. ${ }^{3}$ CAS Center for Excellence in Molecular Plant Sciences, Shanghai Institutes for Biological Sciences (SIBS), Chinese Academy of Sciences, Shanghai, China. ${ }^{4}$ University of Chinese Academy of Sciences, Shanghai, China. ${ }^{5}$ Center for Microbial Ecology and Technology (CMET), Ghent University, Coupure Links 653, Gent 9000, Belgium.

Received: 5 March 2021 Accepted: 8 July 2021

Published online: 23 July 2021

\section{References}

1. Patz JA, Daszak P, Tabor GM, Aguirre AA, Pearl M, Epstein J, Wolfe ND, Kilpatrick AM, Foufopoulos J, Molyneux D. Unhealthy landscapes: policy recommendations on land use change and infectious disease emergence. Environ Health Perspect. 2004;112:1092.

2. Jones KE, Patel NG, Levy MA, Storeygard A, Balk D, Gittleman JL, Dzszak P. Global trends in emerging infectious diseases. Nature. 2008;451:990-3.

3. Gottdenker NL, Chaves LF, Calzada JE, Saldana A, Carroll CR. Host life history strategy, species diversity, and habitat influuence Trypanosoma cruzi vector infection in changing landscapes. PLoS Negl Trop Dis. 2012;6:e1884.

4. Rulli MC, Santini M, Hayman DT, D'Odorico P. The nexus between forest fragmentation in Africa and Ebola virus disease outbreaks. Sci Rep. 2017;7:41613.

5. Ray AM, Sepulveda AJ, Irvine KM, Wilmoth SKC, Thoma DP, Patla DA. Wetland linked to variations in snowmelt runoff across grand teton and yellowstone national parks. Sci Total Environ. 2019;666:1188-97.

6. Melville DS, Choi C-Y. Reactions of bar-tailed godwits limosa lapponica to apparent capture by clams. Wader study group bulletin. 2013;120:205-7.

7. Fisheries Bureau of Ministry of Agriculture (FBMA). China fishery statistical yearbook. Beijing: China Agriculture Press; 2017.

8. Valiela I, Bowen JL, York JK. Mangrove forests: one of the world's threatened major tropical environments. BioScience. 2001;51:807-15.

9. Fu S, Yang Q, He F, Lan R, Ha J, Ni P, Liu Y, Li R. National safety survey of animal-use commercial probiotics and their spillover effects from farm to humans: an emerging threat to public health. Clin Infect Dis. 2020;70:2386-95. https://doi.org/10.1093/cid/ciz642.

10. Scallan E, Mahon BE, Hoekstra RM, Griffin PM. Estimates of illnesses, hos pitalizations and deaths caused by major bacterial enteric pathogens in young children in the United States. Pediatr Infect Dis J. 2013;32:217-21.

11. Hamilton KA, Chen A, de-Graft Johnson E, Gitter A, Kozak S, Niquice C, Zimmer-Faust AG, Weir MH, Mitchell J, Gurian P. Salmonella risks due to consumption of aquaculture-produced shrimp. Microb Risk Anal. 2018:9:22-32.

12. Lutz C, Erken M, Noorian P, Sun S, Mcdougald D. Environmental reservoirs and mechanisms of persistence of Vibrio cholerae. Front Microbiol. 2013;4:375.

13. Vezzulli L, Grande C, Reid PC, Hélaouët P, Edwards M, Höfle MG, Pruzzo C. Climate influence on Vibrio and associated human diseases during the past half-century in the coastal North Atlantic. PNAS. 2016;113:E5062-71.

14. Austin $\mathrm{B}$, Zhang $\mathrm{XH}$. Vibrio harveyi: a significant pathogen of marine vertebrates and invertebrates. Lett Appl Microbiol. 2006;43:119-24.

15. Gao X, Miao Z, Li X, Chen N, Gu W, Liu X, Yang H, Wei W, Zhang X. Pathogenicity of non-O1/ O139 Vibrio cholerae and its induced immune response in Macrobrachium rosenbergii. Fish Shellfish Immunol. 2019;92:300-7

16. Fu S, Wei D, Yang Q, Xie G, Pang B, Wang Y, Lan R, Wang Q, Dong X, Zhang $X$, et al. Horizontal plasmid transfer promotes the dissemination of Asian acute hepatopancreatic necrosis disease and provides a novel mechanism for genetic exchange and environmental adaptation. mSystems. 2020;5:e00799-19.

17. Patel A, Jeyasekaran G, Jeyashakila R, Anand T, Wilwet L, Pathak N, Malini $\mathrm{AH}$, Neethiselvan N. Prevalence of antibiotic resistant Salmonella spp. strains in shrimp farm source waters of Nagapattinam region in South India. Mar Pollut Bull. 2020;155:111171.

18. Zhou R, Zeng S, Hou D, Liu J, Weng S, He J, Huang Z. Occurrence of human pathogenic bacteria carrying antibiotic resistance genes revealed by metagenomic approach: A case study from an aquatic environment. J Environ Sci (China). 2019;80:248-56.

19. Duran GM, Marshall DL. Ready-to-eat shrimp as an international vehicle of antibiotic-resistant bacteria. J Food Prot. 2005:68:2395-401.

20. Zhang S, Ma Z, Choi CY, Peng H, Bai Q, Liu W, Tan K, Melville DS, He P, Chan YC. Persistent use of a shorebird staging site in the Yellow Sea despite severe declines in food resources implies a lack of alternatives. Bird conservation international. 2018:28:534-48.

21. Fu S, Hao J, Yang Q, Lan R, Wang Y, Ye S, Liu Y, Li R. Long-distance transmission of pathogenic Vibrio species by migratory water birds: a potential threat to the public health. Sci Rep. 2019;9:16303.

22. Wolfe N, Daszak P, Kilpatrick A, Burke D. Bushmeat hunting, deforestation, and prediction of zoonotic disease emergence. Emerg Infect Dis. 2005;11:1822-7.

23. López-Pérez M, Jayakumar JM, Haro-Moreno JM, Zaragoza-Solas A, Reddi G, Rodriguez-Valera F, Shapiro OH, Alam M, Almagro-Moreno S, Laub MT. Evolutionary model of cluster divergence of the emergent marine pathogen Vibrio vulnificus: from genotype to ecotype. mBio. 2019;10:e02852-18.

24. Qin X, Wu S, Hao M, Zhu J, Ding B, Yang Y, Xu X, Wang M, Yang F, Hu F. The colonization of carbapenem-resistant Klebsiella pneumoniae: epidemiology, resistance mechanisms, and risk factors in patients admitted to intensive care units in China. J Infect Dis. 2020;221(Suppl 2):S206S214. https://doi.org/10.1093/infdis/jiz622

25. Sun Z, Sun W, Tong C, Zeng C, Yu X, Mou X. China's coastal wetlands: conservation history, implementation efforts, existing issues and strategies for future improvement. Environ Int. 2015;79:25-41.

26. Pulliam JRC, Epstein JH, Dushoff J, Rahman SA, Bunning M, Jamaluddin $A A$, Hyatt AD, Field HE, Dobson AP, Daszak P. Agricultural intensification, priming for persistence and the emergence of Nipah virus: a lethal batborne zoonosis. J R Soc Interface. 2011;9:89-101.

27. Moberg F, Rönnbäck P. Ecosystem services of the tropical seascape: interactions, substitutions and restoration. Ocean Coastal Management. 2003;46:27-46

28. Sanh NV, Xuan VT, Phong TA. History and Future of Farming Systems in the Mekong Delta. In: Xuan VT, Matsui S, editors. Development of farming systems in the Mekong Delta of Vietnam. Ho Chi Minh City, pp.: JIRCAS, CTU \& CLRRI; 1998. pp. 16-80.

29. Stevenson NJ. Disused shrimp ponds: options for redevelopment of mangroves. Coastal management. 1995;25:425-35. 
30. Ludden C, Raven KE, Jamrozy D, Gouliouris T, Blane B, Coll F, de Goffau M, Naydenova P, Horner C, Hernandez-Garcia J, Wood P, Hadjirin N, Radakovic M, Brown NM, Holmes M, Parkhill J, Peacock SJ. One health genomic surveillance of Escherichia coli demonstrates distinct lineages and mobile genetic elements in isolates from Humans versus Livestock. mBio. 2019;10(1):e02693-18. https://doi.org/10.1128/mBio.02693-18

31. Chen W, Xie Y, Xu J, Wang Q, Gu M, Yang J, Min Z, Wang D, Shi C, Shi X. Molecular typing of Vibrio parahaemolyticus isolates from the middleeast coastline of China. Int J Food Microbiol. 2012;153:402-12. doi:https:// doi.org/10.1016/j.ijfoodmicro.2011.12.00.

32. Garzio-Hadzick A, Shelton DR, Hill RL, Pachepsky YA, Guber AK, Rowland R. Survival of manure-borne E. coli in streambed sediment: effects of temperature and sediment properties. Water Res. 2010;44:2753-62.

33. Sousa OV, Macrae A, Menezes FG, Gomes NC, Vieira RH, MendonçaHagler LC. The impact of shrimp farming effluent on bacterial communities in mangrove waters, Ceará, Brazil. Mar Pollut Bull. 2006:52:1725-34.

34. Yang W, Jeelani N, Cai A, Cheng X, An S. Coastal reclamation alters soil microbial communities following different land use patterns in the Eastern coastal zone of China. Sci Rep. 2021;11(1):7265.

35. Defoirdt T. Implications of ecological niche differentiation in marine bacteria for microbial management in aquaculture to prevent bacterial disease. PLoS Pathog. 2016;12(11):e1005843.

36. Halpern M, Senderovich Y, Izhaki I. Water birds - the missing link in epidemic and pandemic cholera dissemination? Plos Patho. 2008;4:e1000173.

37. Pretzer C, Druzhinina IS, Amaro C, Benediktsdóttir E, Hedenström I, Hervio-Heath D. High genetic diversity of Vibrio cholerae in the European lake Neusiedler See is associated with intensive recombination in the reed habitat and the long-distance transfer of strains. Environ Microbiol. 2017;19:328-44.

38. Yang HY, Chen B, Barter M, Piersma T, Zhou CF, Li FS, Zhang ZW. Impacts of tidal land reclamation in Bohai Bay, China: ongoing losses of critical Yellow Sea waterbird staging and wintering sites. Bird Conserv Int. 2011;21:241-59.

39. Barman S, Turner JCM, Hasan MK, Akhtar S, El-Shesheny R, Franks J, Walker D, Seiler P, Friedman K, Kercher L, et al. Continuing evolution of highly pathogenic H5N1 viruses in Bangladeshi live poultry markets. Emerg Microbes Infect. 2019;8:650-61.

40. Cabello FC. Heavy use of prophylactic antibiotics in aquaculture: a growing problem for human and animal health and for the environment. Environ Microbiol. 2006;8:1137-44.

41. Fritzsche MA, Hoye BJ. Are migratory animals superspreaders of infection? Integr Comp Biol. 2016;56:260-7.

42. Xu YJ, Gong P, Wielstra B, Si Y. Southward autumn migration of water birds facilitates cross-continental transmission of the highly pathogenic avian influenza H5N1 virus. Sci Rep. 2016;6:30262.

43. Harvell D, Altizer S, Cattadori IM, Harrington L, Weil E Climate change and wildlife diseases: When does the host matter the most? Ecology. 2009;90(4):912-20

44. Tran L, Nunan RM, Redman LL, Mohney CR, Pantoja K, Fitzsimmons DV, Lightner. Determination of the infectious nature of the agent of acute hepatopancreatic necrosis syndrome affecting penaeid shrimp. Diseases of Aquatic Organisms. 2013;105:45-55.

45. Bosshard PP, Santini Y, Grüter D, Stettler R, Bachofen R. Bacterial diversity and community composition in the chemocline of the meromictic alpine Lake Cadagno as revealed by 165 rDNA analysis. FEMS Microbiol Ecol. 2000;31:173-82

46. Bolger AM, Lohse M, Usadel B. Trimmomatic: a flexible trimmer for Illumina sequence data. Bioinfo. 2014;30:2114-20.

47. Bankevich A, Nurk S, Antipov D, Gurevich AA, Dvorkin M, Kulikov AS, Lesin VM, Nikolenko SI, Pham S, Prjibelski AD, et al. SPAdes: a new genome assembly algorithm and its applications to single-cell sequencing. J Comput Biol. 2012;19:455-77. doi:https://doi.org/10.1089/cmb.2012.0021.

48. Aziz RK, Bartels D, Best AA, DeJongh M, Disz T, Edwards RA, Formsma K, Gerdes S, Glass EM, Kubal M. The RAST Server: rapid annotations using subsystems technology. BMC Genomics. 2008;9:75. https://doi.org/10. 1186/1471-2164-9-75.

49. Larsen MV, Cosentino S, Rasmussen S, Friis C, Lund O. Multilocus Sequence Typing of Total-Genome-Sequenced Bacteria. J Clin Microbiol. 2012:50:1355-61.

50. Zankari E, Hasman H, Cosentino S, Vestergaard M, Rasmussen S, Lund O, Aarestrup FM, Voldby LM. Identification of acquired antimicrobial resistance genes. J Antimicrob Chemother. 2012;67:2640-4.

51. Li H, Durbin R. Fast and accurate short read alignment with BurrowsWheeler Transform. Bioinformatics. 2009;25:1754-60.

52. Chan CHS, Octavia S, Sintchenko V, Lan R, SnpFilt. A pipeline for reference-free assembly-based identification of SNPs in bacterial genomes. Comput Biol Chem. 2016;65:178-84.

53. Stamatakis A. RAxML-VI-HPC: maximum likelihood-based phylogenetic analyses with thousands of taxa and mixed models. Bioinfo. 2006;22:2688

54. Swofford DL. Paup - a computer-program for phylogenetic inference using maximum parsimony. J Gen Physiol. 1993;102:A9.

55. Sader HS, Flamm RK, Jones RN. Antimicrobial activity of daptomycin tested against Gram-positive pathogens collected in Europe, Latin America, and selected countries in the Asia-Pacific Region (2011). CLSI document M07-A9. Wayne: Clinical and Laboratory Standards Institute; 2012.

56. Ramirez KS, Leff JW, Barberan A, Bates ST, Betley J, Crowther TW. Biogeographic patterns in below-ground diversity in New York City's Central Park are similar to those observed globally. Proc Biol Sci. 2014;281:20141988.

57. Kembel SW, Jones E, Kline J, Northcutt D, Stenson J, Womack AM, Bohannan BJ, Brown GZ, Green JL. Architectural design influences the diversity and structure of the built environment microbiome. ISME J. 2012;6:1469-79.

58. Wang Q, Garrity GM, Tiedje JM, Cole JR. Naive Bayesian classifier for rapid assignment of rRNA sequences into the new bacterial taxonomy. Appl Environ Microbiol. 2007;73:5261-7.

59. Caporaso JG, Kuczynski J, Stombaugh J, Bittinger K, Bushman FD, Costello EK, Fierer N, Peña AG, Goodrich JK, Gordon. J.I. QIIME allows analysis of high-throughput community sequencing data. Nat Methods. 2010;7:335-6.

60. Louca S, Parfrey LW, Doebeli M. Decoupling function and taxonomy in the global ocean microbiome. Science. 2016;353:1272-7.

61. Faith DP. Conservation evaluation and phylogenetic diversity. Biol Cons. 1992:61:1-10.

62. Team CR. R: A language and environment for statistical computing. Vienna: R Foundation for Statistical Computing; 2016

63. Tabatabaei M, Hemati Z, Moezzi M, Azimzadeh N. Isolation and identification of Legionella spp. from different aquatic sources in south-west of Iran by molecular \&culture methods. Mol Biol Res Commun. 2016;5:215-23.

64. Makovcova J, Babak V, Slany M, Slana I. Comparison of methods for the isolation of mycobacteria from water treatment plant sludge. Antonie Van Leeuwenhoek. 2015;107:1165-79.

65. Parks DH, Tyson GW, Hugenholtz P, Beiko RG. STAMP: Statistical analysis of taxonomic and functional profiles. Bioinformatics. 2014;30:3123-4.

\section{Publisher's Note}

Springer Nature remains neutral with regard to jurisdictional claims in published maps and institutional affiliations. 